Conclusion In the largest regional series on FRED for intracranial aneurysms to date, data suggest that treatment with the Flow Re-direction Endoluminal Device is safe and efficacious, with complication rates comparable with others FD available. Our local results are promising but larger series with longterm follow-up are required to determine its superiority.

Disclosures B. Pabon: 2; C; Microvention, Medtronic, Stryker. C. Diaz: None. M. Fonseca: None. N. Lobelo: None. J. Holguin: None. J. Mejia: None. O. Vargas: None. M. Patiño: None. N. Serna: None.

\section{P-022 IMPACT OF WEB ON PROCEDURE TIMES, ANESTHESIA AND RADIATION FOR TREATMENT OF WIDE NECK BIFURCATION ANEURYSMS}

A Rai ${ }^{*}$, R Turner, S Boo. Interventional Neuroradiology, West Virginia University, Morgantown, WV

\subsection{6/neurintsurg-2019-SNIS.58}

Objective The approval of WEB adds another option for treatment of wide neck bifurcation (WNB) aneurysms. The objective of this study was to compare the procedure times and radiation dose when using WEB versus stent-coil for WNB aneurysms in our early experience.

Methods

Four procedure variables were analyzed Operating room (OR) time was the duration from patient room arrival to room exit. Anesthesia time was from intubation to extubation. Procedure time was from groin puncture to closure. Radiation exposure was the fluoroscopy time and radiation dose for each procedure. All these were obtained from the procedure logs for 22 patients treated with WEB and 21 patients consecutively treated prior to WEB with stent-coiling. Patients with aneurysms greater than $10 \mathrm{~mm}$ in average width were excluded to level the comparison as larger aneurysms requiring more coils could take longer and the upper width size limit for WEB is currently at $10 \mathrm{~mm}$.

Results The average width and height of the aneurysms in the two cohorts was similar (Width $=5.9( \pm 2.2) \mathrm{mm}$ for the stentcoil versus $5.2( \pm 1.6) \mathrm{mm}$ for the WEB-group, $\mathrm{p}=0.2$; Height $=6.8( \pm 3.1) \mathrm{mm}$ for the stent-coil versus $5.8( \pm 1.7) \mathrm{mm}$ for the WEB-group, $p=0.2$ ). The OR, anesthesia and procedure times were significantly lower in the WEB-group compared to the stent-coil group (figure-1). The fluoroscopy time and the radiation dose was also significantly lower in the WEB-group versus the stent-coil group (figure-1).

Conclusion The use of WEB in WNB aneurysms significantly reduced OR, anesthesia and procedure times versus stent-coiling for similar sized aneurysms. Radiation dose and fluoroscopy times were also significantly reduced. For the WEB group these times are expected to be independent of aneurysm size whereas stent-coiling may be associated with longer times for larger aneurysms.

Disclosures A. Rai: 2; C; MicroVention, Stryker. R. Turner: None. S. Boo: 2; C; Stryker.

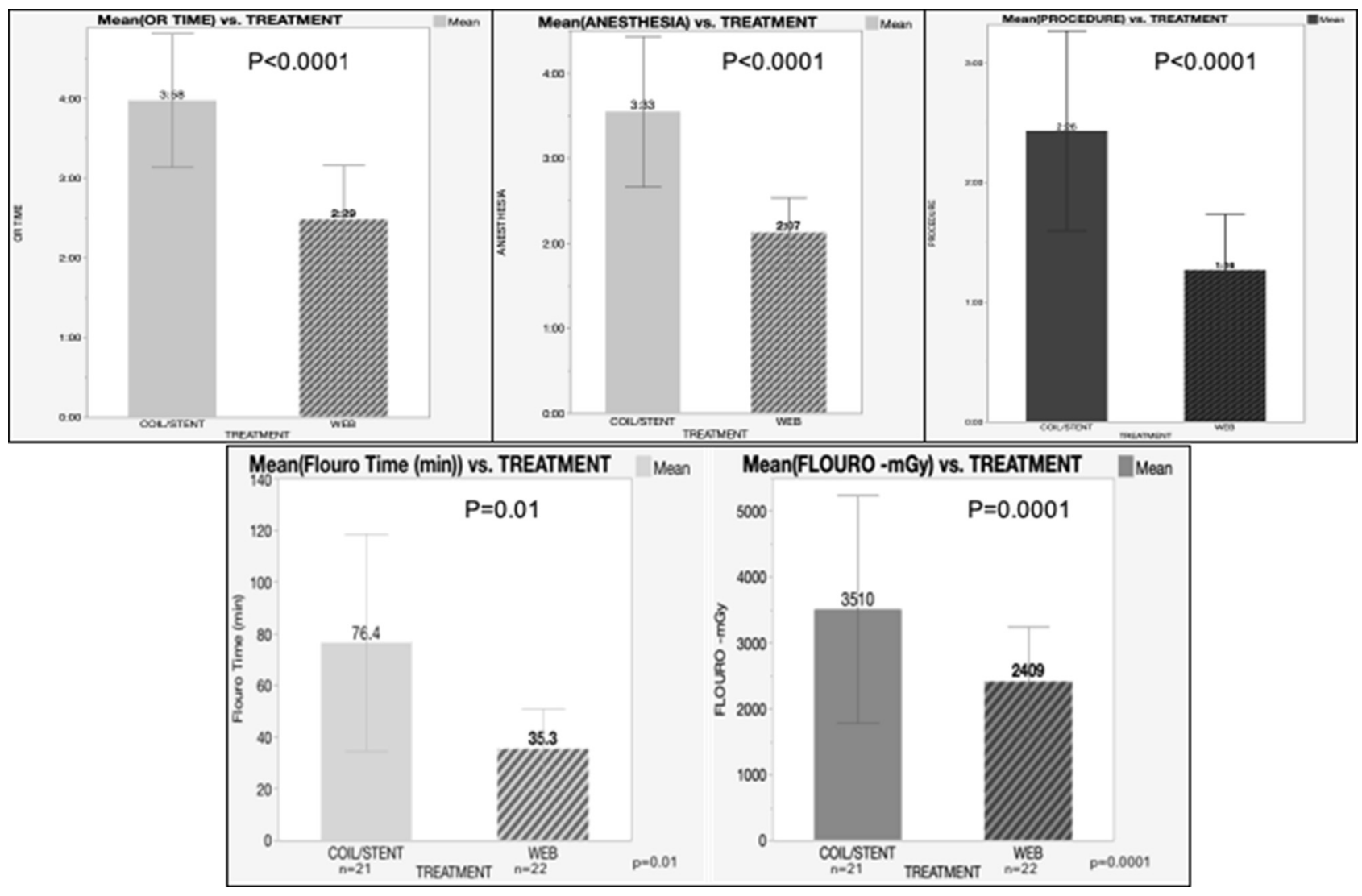

Abstract P-022 Figure 1 